\title{
THE PRIMITIVE PORES OF POLYODON SPATHULA (WALBAUM)
}

\author{
HENRY F. NACHTRIEB
}

Professor of Animal Biology and Head of the Department, The University of Minnesota

TWELVE FIGURES

Polyodon spathula, popularly called Spoonbill and Paddlefish, is one of the most individualistic and interesting representatives of the living Ganoids. Among the striking external features are hundreds of groups of black spots on both the dorsal and ventral surface (excepting a narrow area along the mid-dorsal and midventral line) of the bill. The spots of a group may be arranged in two to five, or more, clearly marked smaller, primary groups of two to ten individual dots. Now and then a single spot is located quite apart from others. As a rule the spots are grouped in the area corresponding to or lying over the meshes of the bony network of the bill. They rarely lie immediately over a plate of bone. Figs. 1, 2, 3, 4 will give a better idea of the arrangement and distribution of these spots on the bill of Polyodon than can be gained from a description. Similar groups of spots are found on the outer surface of the operculum, about the eye and other re gions of the head. Their distribution on the operculum and side of the head is shown in fig. 5. A large group may contain as many as sixty dots, but as a rule a group contains less than half that number, particularly on the bill. The largest groups have been found on the operculum. There is, however, considerable insignificant variation among the individuals in both the size of the groups and their distribution on the operculum and other parts of the head. On the bill the size of the groups of spots and their distribution are more or less determined by the bony network of the bill. Figs. 1 and 2 show their distribution on a large 

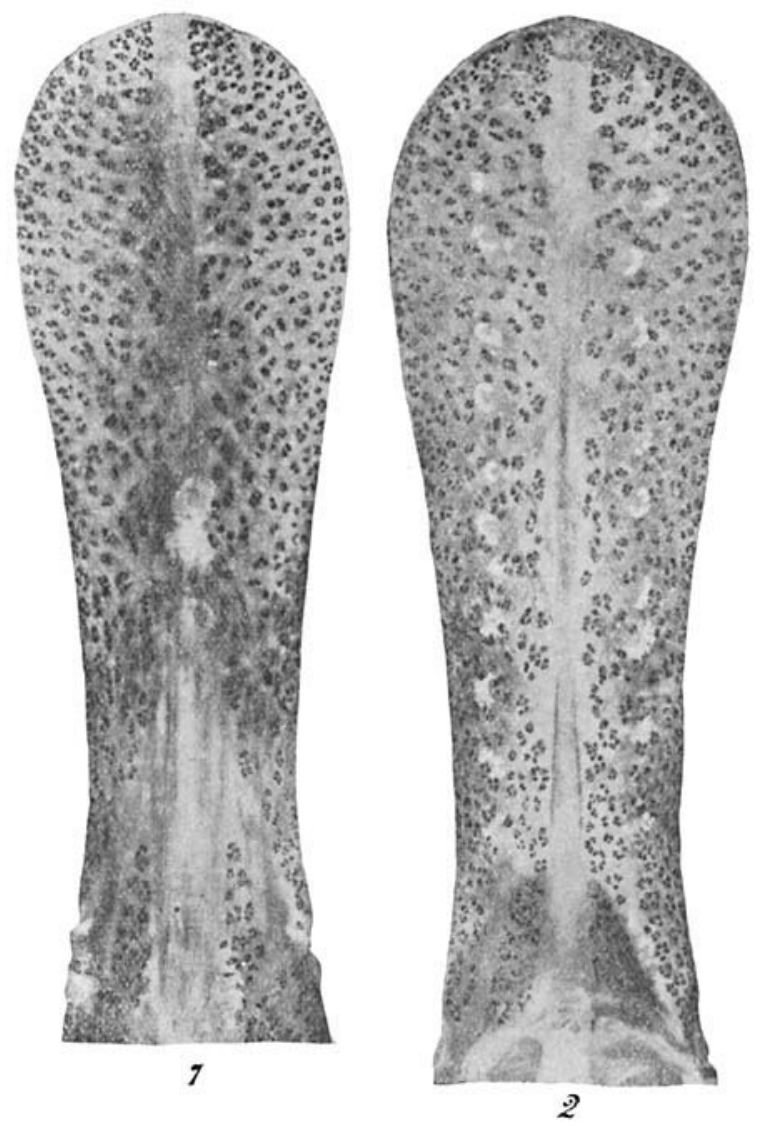

Figs. 1 and 2. Photographs of the dorsal and ventral surface respectively of a bill $300 \mathrm{~mm}$. long from the tip of the bill to the eye. The fish was a little more than one meter long from the tip of the bill to the tip of the dorsal lobe of the tail. The clusters of lateral line branches shown in fig. 2 were painted white to make them stand out more clearly. As a rule they are inconspicuous. Fig. 2 was inadvertently photographed on a slightly larger scale than was fig. 1.

Figs. 3 and 4. Photographs of the two halves of a portion of a bill cleared in caustic potash. The black lines represent the sheaths of pigment cells surrounding the blood vessels. The groups of black spots represent the groups of primitive pores. In fig. 4 the lines and spots were accentuated with India ink. Fig. 3 has not been retouched. 


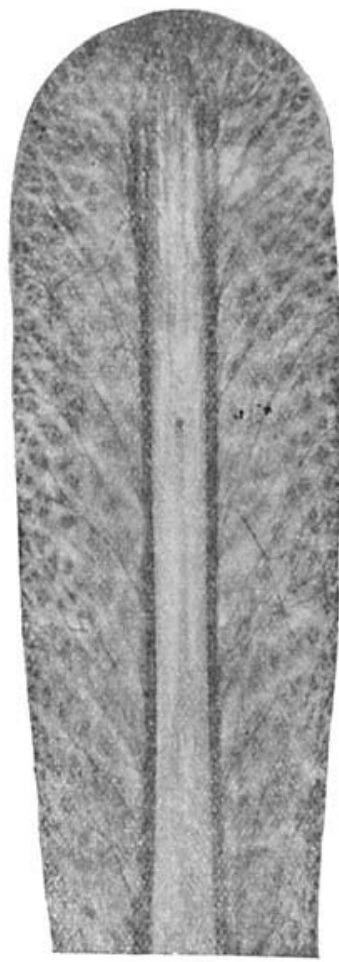

了)

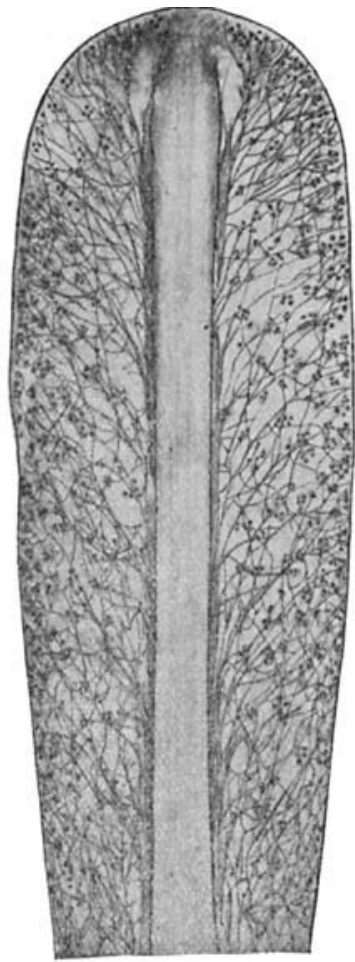

4

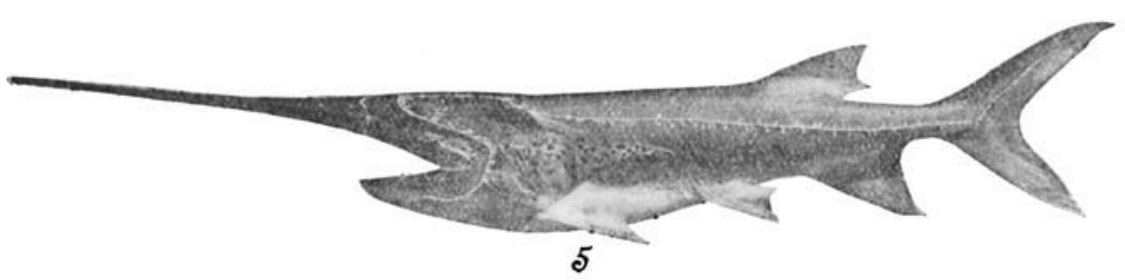

Fig. 5. Photograph of a Polyodon spathula on which the lateral line and its branches and the hyomandibular branch and its branchlets had been painted white. Many of the groups of primitive pores on the side of the head were inked to make them stand out more clearly. The slight humping at the dorsal fin is due to the way the fish was suspended. The fish measured about one meter from the tip of the bill to the tip of the dorsal lobe of the tail. 
bill. Figs. 6 and 7 show in detail the grouping in a small area respectively on an operculum and the dorsal surface of a bill.

Careful examination discloses the fact that each dot represents at least one small pit surrounded by pigment cells, which to the unaided eye appear as one black mass. Toward the free edge of

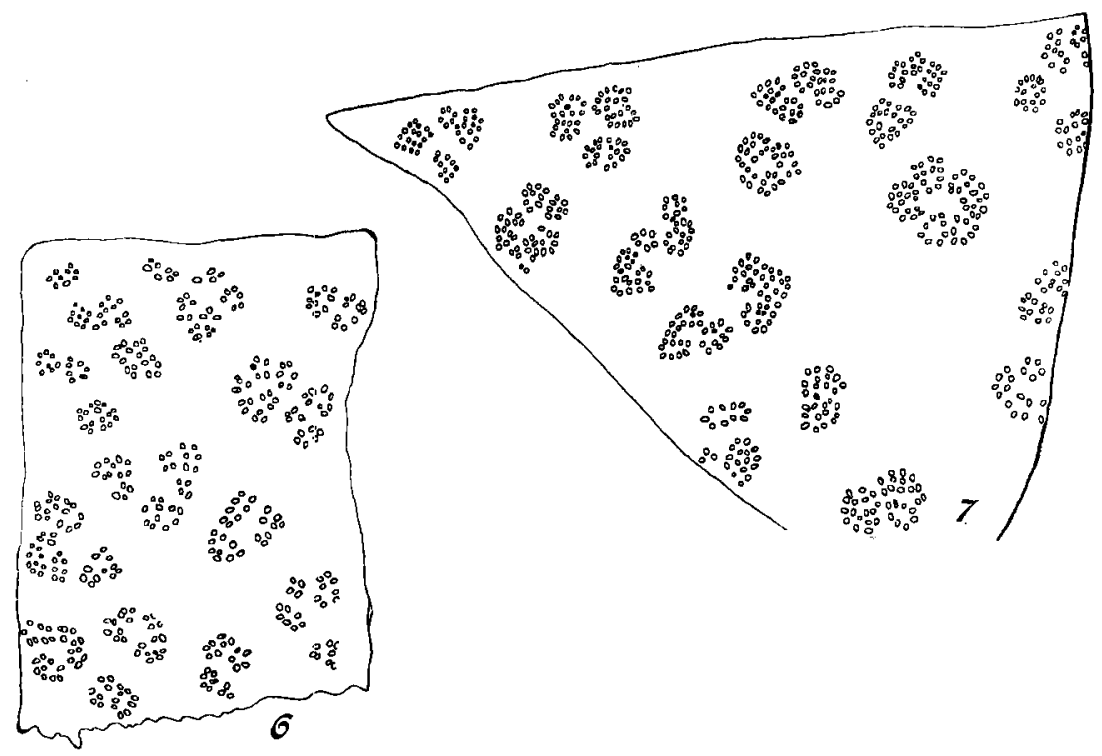

Figs, 6 and 7. Camera lucida sketches showing the grouping of the primitive pores respectively in a small area on the ventral surface of a bill and on the end of an opercular flap. Drawn by Helen A. Sanborn.

the operculum the pigment cells often are less abundant about the pits than they are elsewhere. In some of the groups of pits the pigment cells are almost wholly absent, and in such places the pits can be located only by close inspection. All the pits here noted were called primitive pores by Collinge, ${ }^{1}$ and they will be so termed in this article. For convenience I shall also refer to them as pits. There are from fifty to seventy-five thousand of these pits on the bill, head and operculum of Polyodon.

${ }_{1}$ The Sensory Canal System of Fishes. Part I.-Ganoidei. By Walter Edward Collinge. Q. J. Mic. Science, vol. 36, New Series, 1894. 
The primitive pores are simple epithelial invaginations about two hundred microns deep and about seventy-five to one hundred microns in transverse diameter. Definite measurements are given of several pits in connection with fig. 9 . The primitive pores usually contain some mucous and not infrequently they are full of mucous. The mouth or opening is usually smaller than the diameter of the pit near its bottom. As a rule each pit has its own opening or mouth, but not infrequently two pits, and occasionally three, have a common opening. In form the pit varies from a cylindrical invagination with an almost flat bottom to a more or less pronounced flask-shaped depression with a more or less concave bottom. None of the pits have what might be called a distinct neck. Indeed, as will appear later on, each pit presents just two distinct regions - the differentiated bottom and the undifferentiated region above the bottom. Figs. 8 and 9 show groups of primitive pores respectively in transverse and longitudinal section.

As intimated above each primitive pore is more or less completely surrounded by branched pigment cells, which are abundant in nearly all parts of the body. Fig. 8 gives some idea of the distribution of pigment cells among the pits near the bottom of the pits. Lymph sinuses, blood vessels and nerves are abundant in the subcutaneous connective tissue. Figs. 3 and 4 show the distribution of the blood vessels in the neighborhood of the primitive pores of the bill. The vessels are surrounded by a more or less dense network of branched pigment cells and consequently stand out as black lines. Nerves usually accompany these blood vessels but $I$ have never seen a nerve going to the bottom of a primitive pore.

On the ventral surface of the bill there is a double row of groups of pores that open into small canals connected with branches of the lateral line. These groups are well shown in fig. 2. As a rule they are not very evident, but on some bills they are quite conspicuous. A comparison of the branchlets of the lateral line, shown in fig. 5, with these rather striking structures of the bill, shown in fig. 2, will at once suggest that the clusters of pores and tubes on the ventral surface of the bill represent close groups 

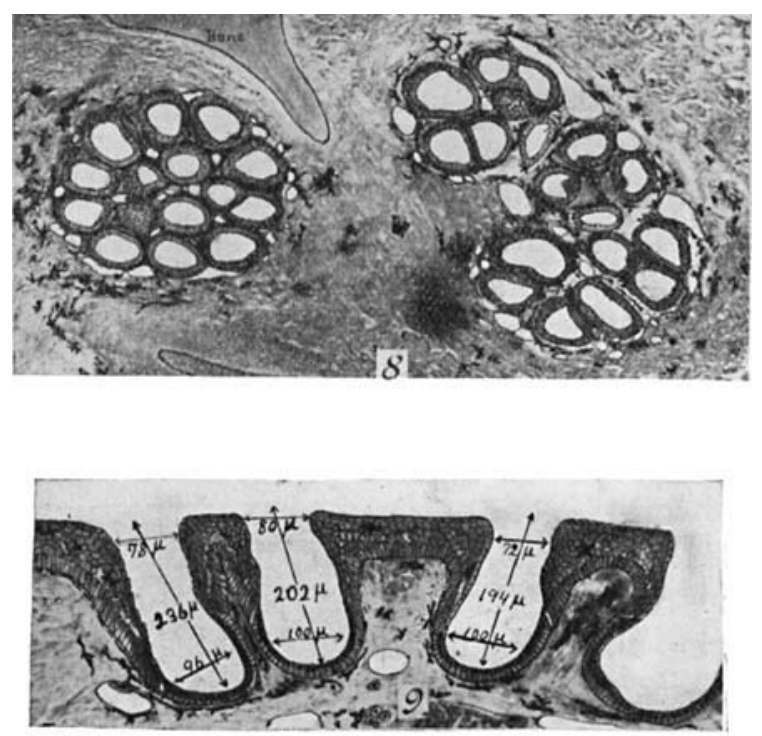

Fig. 8. Photographs of a horizontal or transverse section of several groups of primitive pores showing the distribution of the pigment cells, the lymph spaces and blood vessels among the primitive pores. The section passed through the pores a little above the plane of the floor of most of the pits. The photograph was partially inked to bring out certain features more clearly than others. Photographs with a Zeiss aa, plate about six feet from the object. Figure one-half the size of the photograph.

Fig. 9. Photograph of a longitudinal section of four primitive pores showing the general form of the pits. All the blood vessels, excepting the one next to the number of the figure are empty. A small nerve is shown at the left of the number. The photograph was partially inked, and the reproduction here is one-half the size of the original.

The dimensions of the pits were determined with a Zeiss Screw Stage Micrometer. The photograph was made with a $\mathrm{Zciss} \mathrm{C}$ objective, the plate about five feet from the slide.

of branchlets like those of the lateral line. I have never found any of the branches or branchlets of the lateral line system in any way in communication with a primitive pore. The primitive pores are notand, I believe, never have been in communication with the lateral line system. Incidentally it may be remarked that the lateral line of the Polyodon shown in fig. 5 is typical, and effectively 
corrects some of the erroneous conclusions and figures Collinge based upon his poorly preserved material.

Collinge described and figured the primitive pores as distinct sense organs, each having a definite nerve. The material upon which his description and accompanying figures were based was admittedly poorly preserved, but imagination and a preconception of the structure of a sense organ supplied what the material lacked. The only thing in Collinge's figures that corresponds to fact is the invagination, and even this is not altogether correct. These figures offer an excellent illustration of the danger of basing any description and figures of histological structure upon poorly preserved material.

In 1905, during the session of the American Society of Zoölogists at Ann Arbor, I pointed out Collinge's errors and gave some evidence discrediting the generally accepted view that the primitive pores are sense organs.

In $1906 \mathrm{Kistler}^{2}$ published a paper in which the primitive pores are presented as distinct sense organs. The floor of the primitive pore is described and figured as lined by a single layer of two types of cell-one a clear "supporting cell" and the other a darker, club-shaped "sensory cell" with a definite "slender conical process" on its free surface and a distinct innervation. Fig. 12 is a free copy of Kistler's fig. 6, which illustrates his two types of cells. The nerve fibrils have been omitted.

In 1907 I presented a brief paper on the lateral line system of Polyodon at the VIIth International Zoölogical Congress. In this paper I concluded my remarks on the primitive pores with the following statement: "The abundance of the peculiar mucous-like secretion found in many specimens, and the character of the epithelium, indicate at least that the function is not primarily that of a special sense organ. If the primitive pore is a sense organ at all it is one of low differentiation." The figures accompanying the above, while sufficient for general purposes, are not correct in the details of the epithelium. The following

\footnotetext{
2 The Primitive Pores of Polyodon spathula. By Herbert D. Kistler, B.S., M.D. Jour. Comp. Neur. Psych., vol. xvi, 1906.
} 
account and figures are based upon recently made preparations that I believe present conclusive and irrefutable evidence against the generally accepted view that the primitive pores are distinctive sense organs.

My best material was obtained from the living fish, fresh from the water. Pieces of the bill, operculum and other parts of the head were immediately placed into various hardening fluids. Since the fish has little vitality out of the water in the summer, and the epithelium at this time of the year sloughs off very easily shortly after the death of the fish, prompt hardening of the material is important. Various hardening fluids, such as formalin, formol-corrosive sublimate-acetic acid, trichloracetic acid, Zenker and Gilson fluids were used. Small pieces of the hardened material were imbedded in paraffin, cut into series of sections, three, four, five, seven and ten microns thick, fixed to the slide, variously stained and finally mounted in xylol damar. Some pieces were stained in toto and yielded good general results. The connective tissue is apt to become very tough during the processes of harden.ing and imbedding. It is therefore advisable to limit the material to be cut to the epithelium as far as possible. Sections stained with Heidenhain's iron hematoxylin yielded the clearest positive results and, unless specifically stated otherwise, the following descriptions are based on sections stained by this method. Sections stained with other aqueous, and alcoholic stains, present the same general characters, though not always with the same distinctness.

In sections parallel to the long axis of the primitive pore the epithelium of the bottom of the pit is clearly and sharply marked off from the epithelium lining the rest of the pit. While the epithelium on the floor of the pit is the immediate bone of contention, it is necessary to consider briefly the skin epithelium between the pores and to examine carefully its relation to that of the pore, especially to that lining the floor of the pit.

Just beyond the mouth of the primitive pore the skin epithelium may be ten to fifteen or more cells deep. The outer or surface cells are thin plates. The basal cells are more or less slender columnar cells. In some regions the basal cells are very long and 
slender. Whatever the shape of the basal cell, the nucleus lies in the distal region of the cell. The layers between these two extremes present the usual intermediate cell-forms of a manylayered epithelium. In well stained preparations all the celis, excepting the outermost flat cells, have a blue to blue-gray tint. The nuclei stain more deeply in spots but appear quite clear and present a rather open chromatin network in which one can usually recognize a distinct nucleolus, using the term in a morphological sense only. The cells of the outer two or three layers stain more deeply than the rest, appear much denser and have dense, deeply stained nuclei, which appear like slender rods. This difference in structure and affinity for stains makes the outer layers, when seen under a moderate power, appear like a limiting membrane. Just within the mouth of the pit this apparent limiting membrane disappears, the number of layers of cells becomes reduced and gradually, though rapidly, falls to two near the bottom of the pit. At and within the mouth of the pit the surface cells frequently present finger-like processes which, as a rule, slant obliquely toward the mouth of the pit. In color and consistency these processes frequently remind one of the surface cells of the skin. They represent not a special structure but merely the loosened overlapping edges of the cells. Near the bottom of the pit these processes are usually wanting, though shorter, more delicate and less deeply stained processes may be present on the cells next to the edge of the differentiated bottom epithelium. Aside from the appearance due to the overlapping of the cells, the thickness and plane of the section, these processes appear to be artifacts due to partial maceration or imperfect hardening or after treatment. They appear in greatest profusion in preparations whose general. appearance reminds one of poorly preserved material. In well perserved material, carefully sectioned and carefully mounted, the fingerlike processes are not prominent and not infrequently are absent altogether. On the other hand they are seen in some preparations that otherwise appear well preserved. It is not at all impossible that the conditions within a pit affect the ordinary surface ejpthelium much as warm water acts on the skin of the dead fish. The mucous and other conditions may cause stagna- 
tion and maceration within the pit and thus lead to a lessening of the overlapping edges of the ordinary surface cells. This suggestion occurred to me but recently and I have not had an opportunity of testing it.

Under a medium power, such as a Zeiss $\mathrm{D}$, the epithelium on the floor of the pit presents a line of deeply stained nuclei. The line of demarcation between these deeply stained nuclei and the lighter, less dense nuclei of the cells lining the rest of the pit is sharp. It can be readily recognized in figs. 9 and 11, although it is not as striking here as it is in the sections. At first glance this floor epithelium appears two layered. A careful examination, however, convinces one that it is only one cell deep but composed of two kinds of cells. The more conspicuous and somewhat more abundant cell is a large, relatively clear, columnar cell, less than twice as long as it is wide, with a relatively clear cytoplasm and a deeply stained spherical nucleus containing several nucleoluslike bodies of which three to six may be in view at one focus. This is Kistler's "supporting cell." For reasons that will appear later I shall call it the flagellated cell. The other cell extends out beyond, and more or less covers the outer ends of the contiguous flagellated cells. The cytoplasm of this cell appears more dense; the nucleus is larger, clearer and usually contains but one conspicuous nucleolus-like body. This is Kistler's "sensory cell.". I shall call it the cover cell. The two kinds of cells are very easily distinguished by their nuclei. In both kinds of cells the nucleus lies in the outer portion. In nearly all of the preparations the surface of this differentiated epithelium appears faintly ragged or fuzzy as if covered by bits of mucus.

- Under a Zeiss $2 \mathrm{~mm}$. apochromatic objective of 1.30 N.A. and a number 4 or 6 compensating eye piece the differences just noted become more marked and new distinctive features become evident in well preserved material stained with Heidenhain's iron hematoxylin. The cover cell, shown in detail in fig. 10, is compressed in the middle so that in optical longitudinal section it appears more or less dumbbell-shaped. The nucleus lies in the expanded distal portion of the cell and in optical section appears triangular because the lower part of it lies in the compressed 
region of the cell. It appeai's clear and has a loose, large-meshed network in which there usually is one large nucleolus-like body. The cytoplasm appears homogeneous, sometimes suggesting longitudinal striation in the basal and compressed region of the cell. The base or proximal end is always expanded and in close contact with the basement membrane. In most of my sections the free surface appears more or less fuzzy. This appearance is due to bits of mucus adhering to very short and variable pseudopodia. My reasons for not considering these processes permanent cilia or sensory hairs are: 1, They are indefinite and variable in shape and length; 2 , There are no basal bodies in connection with them; 3 , In many preparations the surface of the cover cell is in intimate connection with the mucus in the pit. In sections showing masses of mucus in the pits the strands of mucus are frequently so intimately related to the surface of the cover cell that it is impossible to determine where the cell sub. stance ends and the mucus begins. In such preparations the free surface of the cover cell is uneven and may have relatively wide projections continued uninterruptedly into masses or shreds of mucus far from the surface of the cell. In sections of material hardened in platino-aceto-osmic and stained with iron hematoxylin the mucus in the pit, the cytoplasm of the cover cells and the underlying ground substance of the connective tissue are stained brown, the connective tissue usually being of a lighter shade than that of the cover cells and mucus. In some cases the mucus is continuous with a similarly colored mass occupying the place of a cover cell and extending down to the basement membrane, looking as if the cover cell had become converted into one mass of mucus. The mucus is never seen in such intimate connection with a flagellated cell. In some of my formalin-gold chloride preparations the surface of the cover cell is studded with very distinct long processes, three to five times as large as those noted above. They look like stout cylindrical cilia with rounded free ends to which are usually adhering small bits of mucus. In all of these formalin-gold chloride preparations the cell substance is very badly shrunken and in every respect the sections suggest very poor preservation. In fact whenever the sections 
indicate very imperfect killing and hardening or rough aftertreatment the processes on the free surface of the cover cell are more pronounced than they are in well preservedmaterial. In some of the preparations many of the cover cells have a relatively clean cut surface, but none of them appear as clean cut as the surface cells of the ordinary lining epithelium. These facts suggested various experiments which I have not had an opportunity of making.

In view of the facts before me I believe the free surface of the cover cell is more or less plastic and can be temporarily projected into more or less pronounced pseudopodia. The position of the nucleus is not that usually occupied by the nuclei of secretory cells. The shape of the cell is also not typical of secretory cells. But the intimate connection between the mucus and the cell compels the inference of an active relationship between the two. The subcutaneous connective tissue is quite slimy-indeed the general appearance and behavior toward reagents of both the nuclei and the ground substance stamp this as a mucoid supporting tissue. And it may be that the cover cells function primarily as the excretors of the mucus formed in the underlying connective tissue.

The flagellated cell, shown in detail in fig. 10, as a rule has a rounded base, the edge resting on the expanded bases of contiguous cover cells. As a rule the base of the cell is slightly shrunken away from the basement membrane. This condition is so common in even apparently perfectly preserved material that these spaces must be looked upon as normal lymph spaces. The flagellated cell differs from all other epithelial cells in that its cytoplasm below and around the lower half of the nucleus contains distinct loosely distributed, granules, which stain more deeply than the rest of the cell substance but not as deeply as the chromatin granules in the nucleus. In sections of platino-aceto-osmic material stained with iron hematoxylin these granules have a deep blue color. They are quite uniform in size and generally appear more or less spherical. In many cells the granules appear to be wanting in a narrow area next to the cell wall, and the cell below the nucleus presents a clear unstained peripheral area sur- 


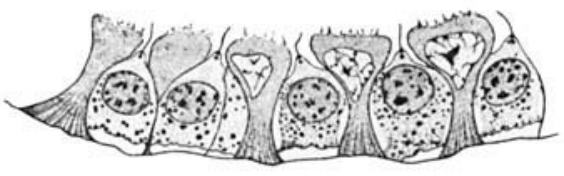

10

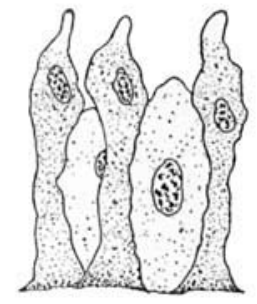

12

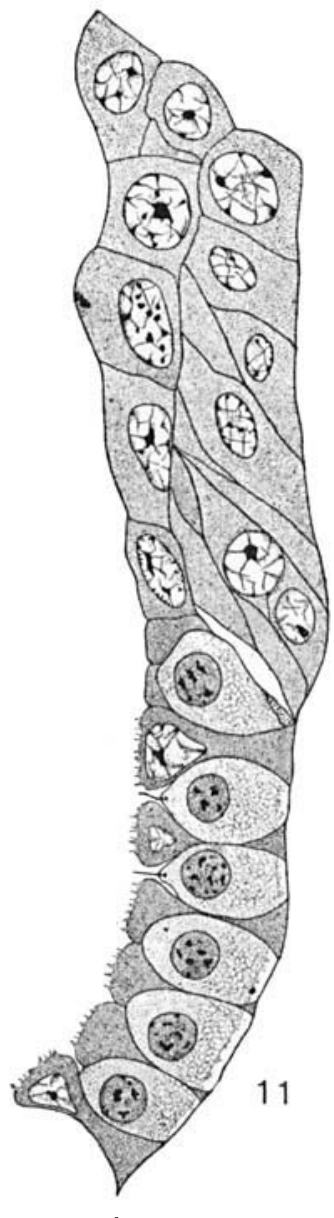

Fig. 10. Camera lucida drawing of several of the diferentiated cells of the floor of a primitive pore. The drawing was outlined on the table with a Zeiss $2 \mathrm{~mm}$. apochromatic objective of $1.30 \mathrm{~N}$.A. and compensating eye piece number 6 . Drawn by Helen A. Sanborn.

The second flagellated cell from the right measured 5 microns from the tip of the cone to the basement membrane and about $3 \frac{1}{2}$ microns through its largest diameter. The flagellum was barely 2 microns long. The cover cell to the right of this flagellated cell extends about 1 micron beyond the tip of the cone of the flagellated cell. Stained with iron hematoxylin.

Fig. 11. A camera lucida drawing made on the table to show the relations of the differentiated to the undiferentiated epithelium of a pit. The drawing was made after a section stained with Dominici's eosin-orange G-toluidin blue, which does not bring out the flagella. These have been added in accordance with iron hematoxylin preparations. Zeiss $2 \mathrm{~mm}$. apochromatic objective of 1.30 N.A. and compensating eye piece number 6. Drawn by Helen A. Sanborn.

Fig. 12. Copied from Kistlers's fig. 6, to show his two types of cells. 
rounding a stained and granular inner portion. The free end of the flagellated cell is a short cone in which the cytoplasm is homogeneous and has a faint bluish tint. The apex of the cone is extended as a slender deeply stained flagellum through the opening between the outer ends of the contiguous cover cells. At the base of the flagellum there are two distinct deeply stained basal bodies (diplosome), one below the other and apparently in contact with each other. When I first saw this flagellum I interpreted it as a sensory hair, but the two basal bodies militated against this interpretation. Moreover it was found curved in various directions, which conditions would not obtain if it were a stiff hair. While I have not had an opportunity of verifying this interpretation with observations on living material I do not hesitate in declaring the process a flagellum, because all the morphological features are in accord with it. Having been convinced of the presence of the flagellum in good iron hematoxylin preparations, one now and then gets suggestions of it in sections stained with Ehrlich-Biondi and other stains; but none of the various stains used, excepting the iron hematoxylin, differentiated the flagellum clearly.

A comparison of fig. 12, representing Kistler's two kinds of cells, with my figs. 10 and 11 and the descriptions given above will convince one that there are irreconcilable differences between the two accounts. I can explain these differences only on the assumption that Kistler based his conclusions entirely upon observations made with objectives of too low power.

In the character of the nucleus and the general appearance of the cytoplasm the cover cell is like the cells of the middle and basal layers of the skin epithelium. The flagellated cell, on the other hand, differs from all of them in every respect. Neither kind of cell has the characters of a distinct sensory cell.

The final conclusion accordingly is: Primarily the primitive pore of Polyodon spathula is an excretory organ that throws off a peculiar mucus, and the differentiated epithelium of the pore consists of a single layer of two kinds of cells on the floor of the pit-the cover or mucus cell and the flagellated cell. 

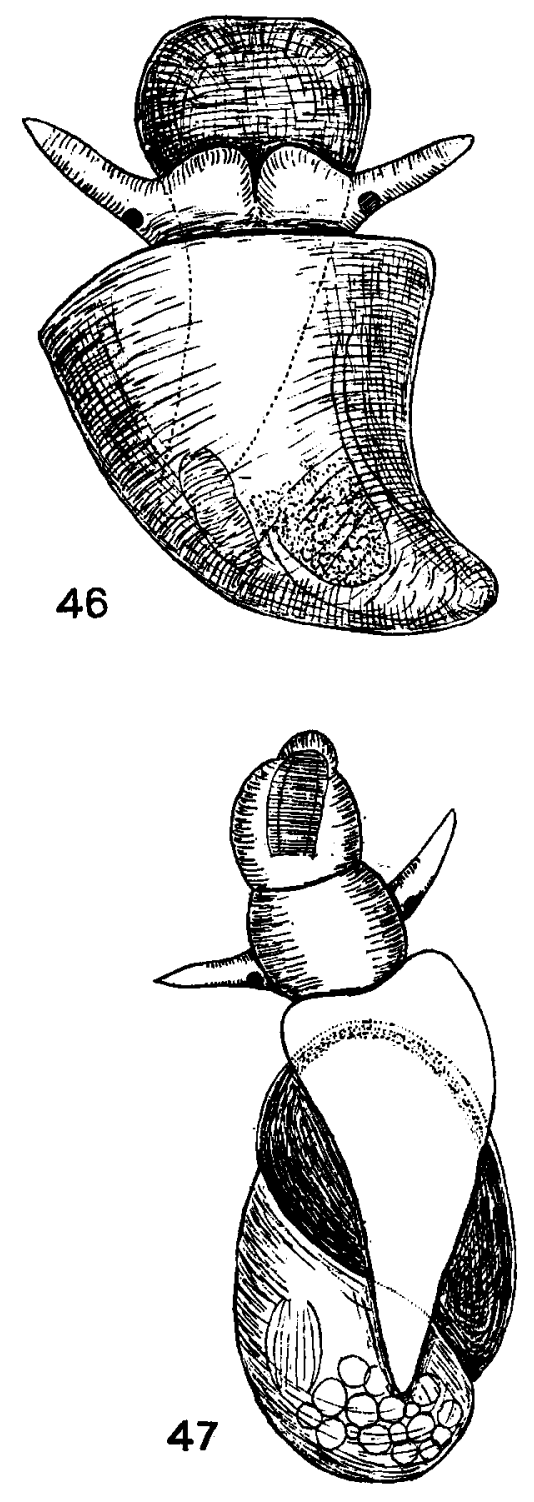